\title{
Arrhythmias in Chronic Kidney Disease
}

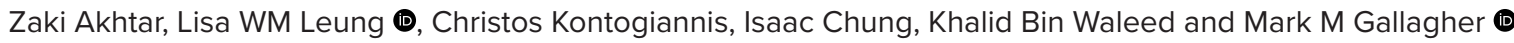

Department of Cardiology, St George's University Hospitals NHS Foundation Trust, London, UK

\begin{abstract}
Arrhythmias cause disability and an increased risk of premature death in the general population but far more so in patients with renal failure. The association between the cardiac and renal systems is complex and derives in part from common causality of renal and myocardial injury from conditions including hypertension and diabetes. In many cases, there is a causal relationship, with renal dysfunction promoting arrhythmias and arrhythmias exacerbating renal dysfunction. In this review, the authors expand on the challenges faced by cardiologists in treating common and uncommon arrhythmias in patients with renal failure using pharmacological interventions, ablation and cardiac implantable device therapies. They explore the most important interactions between heart rhythm disorders and renal dysfunction while evaluating the ways in which the coexistence of renal dysfunction and cardiac arrhythmia influences the management of both.
\end{abstract}

\section{Keywords}

Arrhythmia, chronic kidney disease, sudden cardiac death, dialysis, atrial fibrillation

Disclosure: ZA has received a grant for a research fellowship from Abbott Medical. MMG has received research funding from Attune Medical and Biotronik, and has acted as a consultant and a paid speaker for Boston Scientific and Cook Medical. All other authors have no conflicts of interest to declare.

Received: 7 November 2021 Accepted: 6 December 2021 Citation: European Cardiology Review 2022;17:e05. Dol: https://doi.org/10.15420/ecr.2021.52

Correspondence: Zaki Akhtar, St George’s Hospital, Blackshaw Rd, London SW17 0QT, UK. E: zakiakhtar@nhs.net

Open Access: This work is open access under the CC-BY-NC 4.0 License which allows users to copy, redistribute and make derivative works for non-commercial purposes, provided the original work is cited correctly.

Arrhythmias are common in all age groups, and becoming more prevalent with increasing age.

In young people, most cases reflect the presence of congenital anomalies of the structure or function of the conduction system of the heart. These affect approximately $1 \%$ of the general population and, although seen in patients with renal conditions, they have no important association with chronic kidney disease (CKD).

Acquired conditions of the atrial and ventricular myocardium accumulate with age and cause atrial and ventricular tachyarrhythmias and bradyarrhythmias. AF is the most common sustained arrhythmia by far; it increases sharply with age and affects $1.5 \%$ of the general population at age $55-59$ years and $27 \%$ at age $>85$ years. ${ }^{1}$ Sustained and recurrent ventricular arrhythmias are less common, but are important as sudden death is often due to ventricular tachyarrhythmia. Complete atrioventricular block and other forms of bradyarrhythmia are common and increase sharply with age.

CKD is even more prevalent than sustained arrhythmia and is associated with an excess of acquired arrhythmia of multiple types, and AF in particular. ${ }^{2}$ Sudden death is also more common in CKD and accounts for around one-quarter of deaths in dialysis patients. ${ }^{3}$

Rigorous monitoring can detect a higher incidence of arrhythmia than is evident clinically. Physical or electrocardiographic examination performed in response to symptoms catches a minority of events. In the ARIC study, a 2-week cardiac monitor recorded a high prevalence of non-sustained ventricular tachycardia (30.2\%) and AF (7.4\%) in patients with CKD, while ectopy was present in $>90 \%$ of patients. ${ }^{4}$
The most intensive monitoring is that provided by an implanted device. Rautavaara et al. studied 71 dialysis patients who were asymptomatic for arrhythmia; in a follow-up of 34 months, they detected AF in 51\% of patients, significant bradycardia in $24 \%$ and ventricular tachycardia in $23 \% .^{5}$

\section{Mechanisms of Arrhythmia in Renal Failure Common Causes}

Renal and cardiac tissue share a vulnerability to damage from conditions that are common throughout the world (Figure 1 ).

Diabetes and hypertension each account for a large proportion of arrhythmias in the general population, particularly AF. Both conditions are also responsible for a large proportion of cases of end-stage renal failure.

In both cases, CKD and AF are usually late effects of the underlying condition, but that underlying condition commonly goes undiagnosed until the consequences bring it to light.

\section{Uncommon Causes}

A number of uncommon and rare syndromes are associated with both arrhythmia and CKD. Despite this rarity, they are important because prompt recognition may permit life-extending specific treatment.

Fabry's disease is an X-linked lysosomal storage disorder characterised by an accumulation of glycosphingolipids resulting from a deficiency in the enzyme a-galactosidase A. ${ }^{6}$ There is systemic deposition of glycosphingolipids (particularly globotriaosylceramide) including in the cells of the blood vessels, kidneys and heart. ' Cardiac infiltration 
Figure 1: Chronic Kidney Disease with Arrhythmia

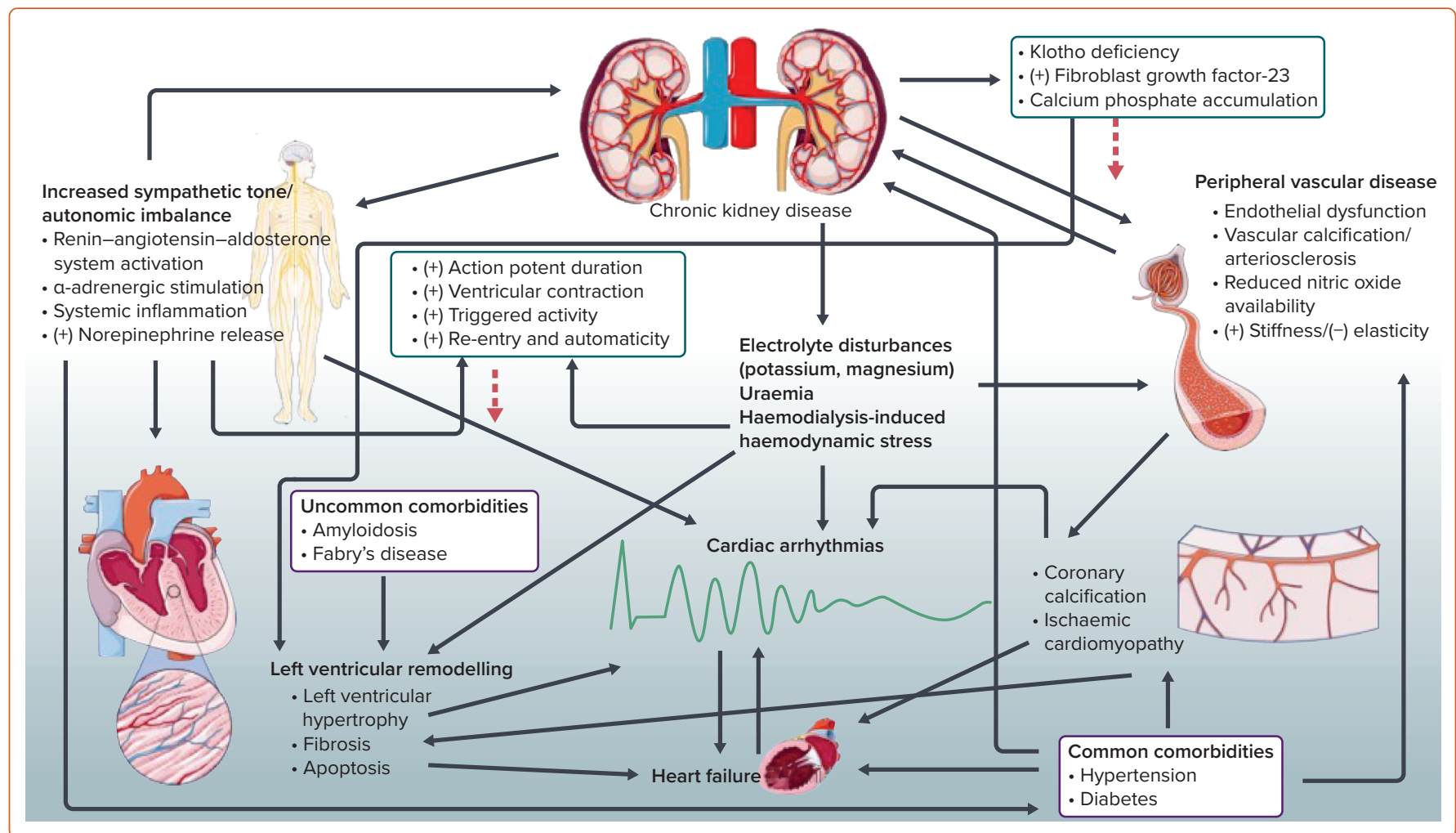

This shows the interactions between chronic kidney disease and arrhythmia and the causes and effects of each.

subsequently results in left ventricular hypertrophy (LVH) secondary to myocardial fibrosis, while renal involvement leads to CKD. Unsurprisingly, cardiac and renal involvement is common in Fabry's disease; a small study of patients (average age 25 years) with Fabry's disease found that $42 \%$ of patients already had CKD at the point of diagnosis and $33.3 \%$ had LVH, suggesting early simultaneous organ involvement. ${ }^{8}$

Arrhythmias in this population are not rare. An observational study has reported a prevalence of $13.3 \%$ in a cohort with Fabry's disease, although it could be higher as the risk worsens with age. ${ }^{8,9}$ Atrial, ventricular and bradyarrhythmias have been confirmed. ${ }^{9,10}$

Myocardial fibrosis is an important substrate for arrhythmias; it is associated with a significantly higher risk of arrhythmias comparatively to patients without fibrosis." The risk of arrhythmias may also be compounded by CKD, which is a pro-arrhythmic clinical state in its own right..$^{2}$ It is therefore unsurprising that the cause of mortality in this group of patients is sudden cardiac death $(S C D)^{13}$ This may be by ventricular tachyarrhythmias or by bradyarrhythmias. ${ }^{10,13}$

Amyloidosis, like Fabry's disease, involves infiltration of both the myocardium and kidneys. There is aggregation and deposition of abnormal protein - amyloid - in the healthy extracellular tissues resulting in organ damage..$^{14}$ Although there are numerous types, the most common in the western world is primary amyloidosis; here, immunoglobulin lightchain proteins are deposited in the affected organs. ${ }^{14,15}$

Renal impairment is a feature of this illness, with associated poor outcomes, even when compared to patients with CKD from other aetiologies..$^{14}$ Nephrotic syndrome ensues progression to end-stage renal failure requiring renal replacement therapy and/or renal transplant.
Despite these interventions, outcomes are unfavourable compared to the general renal failure population. ${ }^{14}$

There is cardiac involvement not only directly through the disease itself but also from renal replacement therapy; progressive haemodialysis can become inefficient at filtration, resulting in $\beta_{2}$-microglobulin deposition from the uraemia. ${ }^{15}$

Cardiac involvement in amyloidosis results in a restrictive cardiomyopathy leading to diastolic left ventricular (LV) dysfunction. Arrhythmias are common in this subgroup of patients, including $A F$, ventricular tachyarrhythmias and conduction abnormalities. ${ }^{16}$ Evidence suggests these patients do not tolerate arrhythmias well due to the poor compliance of the cardiac muscle, which compounds the abnormal filling and ejection of blood. ${ }^{16}$

Arrhythmia management is also difficult because the tissue has abnormal properties following amyloid infiltration. Traditional pharmacological therapy, including $\beta$-blockers, calcium channel blockers and digoxin are poorly tolerated because of the altered haemodynamics, while amiodarone, although it maintains sinus rhythm, is associated with significant side effects. ${ }^{16}$

Catheter ablation, the treatment of choice in many arrhythmias, also is associated with variable outcomes; a small study found a high 1-year arrhythmia recurrence rate following catheter ablation in patients with amyloidosis compared to a similar set of patients without the condition. ${ }^{17}$ Although cardiac failure is the most common cause of mortality in patients with amyloidosis, SCD remains a concern. ${ }^{18}$ SCD can include ventricular arrhythmias but also pulseless electrical activity with electromechanical asynchrony. 


\section{Chronic Kidney Disease, Mineral}

\section{Bone Disorders and Anaemia}

A key feature of CKD is the development of CKD mineral bone disorders. This syndrome is characterised by altered calcium, phosphate, parathyroid hormone, vitamin D and fibroblast growth factor-23 (FGF-23) homeostasis; vascular or soft tissue calcification; and an abnormal bone structure and/ or turnover. ${ }^{19}$ This has a number of effects on the cardiovascular system.

Calcium is a crucial component of myocyte depolarisation and cardiac contractility, while phosphate is central to adenosine triphosphate, the energy-carrying molecule that cells rely upon.

FGF-23 regulates circulating phosphate and vitamin D levels and is associated with poor outcomes. In a study of 795 patients, FGF-23 was strongly associated with LV hypertrophy and increased LV mass index; higher LV mass index is associated with $S C D .{ }^{20,21}$ It also may play a role in the calcification of coronary and peripheral arterial vessels which, in turn, lead to cardiovascular events, thereby exacerbating the risk of SCD. ${ }^{22,23}$

Vitamin D deficiency in CKD has also been found to be associated with cardiac dysfunction. A small prospective control study of 25 patients found that treatment with calcitriol, the active form of vitamin D, markedly reduced LV hypertrophy, resulting in an improvement in LV function. ${ }^{24}$ This indicates that vitamin D plays a significant role in maintaining cardiovascular health in CKD. The authors discovered an association between calcitriol and lower levels of circulating parathyroid hormone and angiotensin II; they proposed that vitamin D may have lowered the level of these neurohormones, which affect LV mass through direct or indirect mechanisms.

Anaemia is common in people with CKD owing to erythropoeitin deficiency and is associated with excess mortality. A large retrospective study suggested that haemoglobin $<6.52 \mathrm{mmol} / \mathrm{l}$ was associated with a mortality risk (HR 5.27) and anaemia was independently associated with mortality and cardiovascular events. ${ }^{25}$

Anaemia in CKD has been associated with LVH, which is an established variable for poor cardiovascular outcomes, and there is evidence suggesting that correction of anaemia results in LVH regression. ${ }^{26}$

However, randomised controlled trials have demonstrated no cardiovascular benefit and, in some cases, worse outcome from correction of anaemia with erythropoeitin. 27,28 This is probably because the benefits from erythropoeitin were negated by the adverse effects from this hormone; promoting red cell production can increase blood viscosity (therefore increase the risk of thrombosis) while attenuating hypertension.

\section{Ischaemia}

Patients with CKD develop ischaemic heart disease at a greater rate than the general population.

Although effective lipid-lowering therapy has been available for decades, re-entry around scarring from previous $\mathrm{Ml}$ is the leading cause of sustained ventricular tachycardia, while ventricular dysfunction from chronic ischaemia is a major cause of heart failure. Between them, these account for a large proportion of SCD.

Atrial arrhythmia is not so strongly linked to ischaemia. Typically, atrial flutter is more common in those with ischaemic heart disease than in agematched controls, while AF occurs at similar rates in both groups.

\section{Electrolytes}

The kidney regulates the excretion or retention of electrolytes and products of metabolism in a continuous manner; dialysis is intermittent, often occurring at intervals of several days. The discontinuous nature of the dialysis process inevitably leads to fluctuations in the levels of any variable that would normally be kept constant by the kidney.

The extent of fluctuation is not itself constant: potassium can accumulate unexpectedly due to changes in diet and variation in the severity of renal dysfunction. During haemodialysis, changes in serum potassium concentration exceeding $1 \mathrm{mmol} / \mathrm{l}$ commonly occur in a period of a few hours. ${ }^{29}$

Trans-membrane ionic gradients drive the electrophysiology of excitable tissues, including the myocardium. Potassium and sodium are involved, but the process is particularly vulnerable to abnormalities in potassium concentration because the resting membrane potential of excitable cells is identical to that of the equilibrium potential of potassium. ${ }^{30}$

Hyperkalaemia is a common feature of renal failure. It produces characteristic abnormalities of the ECG, including peaked T-waves, P-wave flattening and broadening of the QRS duration.

At higher levels of hyperkalaemia, conduction block, bradyarrhythmias, asystole and ventricular arrhythmias can occur. Physiologically, these are related to the raised extracellular potassium concentration; this shortens the myocyte action potential duration (APD) and slows conduction velocity which, in turn, affects myocardial refractoriness. ${ }^{30}$

At high extracellular potassium levels, there is risk of heart block and asystole as the conduction velocity slows, with the shortened APD causing widespread myocardial refractoriness. Ventricular arrhythmias in hyperkalaemia are thought to be re-entrant circuits. It is hypothesised that there is APD discordance in localised regions of the heart with progressive hyperkalaemia. This generates areas of localised block and potentially re-entry. ${ }^{30}$

Hyperkalaemia in CKD can occur catastrophically as part of a constellation of mutually reinforcing processes featuring bradycardia, renal failure, atrioventricular block, shock and hyperkalaemia (BRASH) itself. This cycle can be triggered by the synergy between bradycardia and hyperkalaemia, each of them easily provoked pharmaceutically. ${ }^{31}$

For example, $\beta$-blockers and calcium channel blockers commonly used for controlling arrhythmias can cause bradycardia, which in patients with renal impairment can trigger BRASH syndrome; the risk is believed to be greatest in elderly patients being treated for $A F^{31}$ Once established, this reinforcing sequence can progress to death unless interrupted by supportive care to correct the bradycardia and the hyperkalaemia; temporary pacing may be required as part of this basic support.

\section{Neuropathy}

The autonomic nervous system regulates the heart rate in sinus rhythm and in a less precise manner in AF. Feedback mechanisms mediated by this system appear to have a role in stabilising the electrophysiology of the myocardium, or at least the capacity to destabilise it when the system malfunctions.

A role for autonomic dysfunction in the genesis of AF has been hypothesised, and partial cardiac denervation has been proposed as part of the reason for rhythm stabilisation after AF ablation. 
Autonomic neuropathy is a common consequence of CKD and of the diabetes that often underlies it. ${ }^{32}$ It is reasonable to hypothesise that this neuropathy might contribute to the arrhythmias seen in patients with CKD.

There is evidence suggestive of sympathetic overactivity in CKD. This has numerous adverse effects on the renal-cardiovascular systems. Sympathetic overactivity can exacerbate hypertension, which can sequentially worsen the renal impairment; hypertension contributes to interstitial fibrosis and glomerulosclerosis. ${ }^{33}$ Simultaneously, sympathetic overactivity can cause LVH, directly or indirectly, and it has a known association with cardiac arrhythmias. ${ }^{34}$

There is strong evidence to suggest patients with CKD are more likely to develop AF. ${ }^{35}$ This association was suggested to be causal in a canine model via an autonomic cross link. In this study of 28 dogs, renal sympathetic nerve (RSN) activation mediated pro-fibrillatory effects in the pulmonary veins and atria; RSN activation increased AF inducibility. ${ }^{36}$

Although this is yet to be proven in human studies, it has a theoretical application. Patients with CKD have documented increased RSN activation and RSN denervation has been shown to be an effective therapy for treating $A F^{37}$ A better understanding of the mechanism of RSN hyperactivity may present significant therapeutic strategies for arrhythmias.

\section{Inflammation}

The pathogenesis of AF in CKD could be linked on a molecular level. A recent study has suggested a role for the NLRP-3 inflammasome in the pathophysiology of $A F^{38}$

The NLRP-3 inflammasome is a component of the innate immune system and has been shown to act on cardiomyocytes and atrial fibroblasts. ${ }^{39}$ Activated cardiomyocytes and fibroblasts can secrete inflammatory cytokines, recruit macrophages and other inflammatory cells, and induce

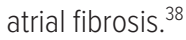

Atrial fibrosis is an arrhythmogenic substrate as it disrupts the normal cellular architecture and therefore impairs normal conduction. This increases conduction heterogeneity, producing re-entrant mechanisms to sustain $\mathrm{AF}^{38,39}$

The significant role of NLRP3 inflammasome in renal injury is recognised and a recent mouse model study (sham-operated versus CKD mice) demonstrated a significantly elevated level of NLRP3 in the cardiac tissue of the CKD mice. ${ }^{40,41}$ Therefore, it is suggested that CKD upregulates NLRP3 in cardiomyocytes and promotes arrhythmias.

\section{Renin-Aldosterone-Angiotensin System}

Patients with CKD have been shown to have inappropriately high reninangiotensin-aldosterone system (RAAS) activity. ${ }^{42}$ Molecules within the RAAS system have been implicated in inflammation, atrial enlargement and atrial fibrosis. ${ }^{43-45}$

First, RAAS has been shown to upregulate inflammatory cytokines such as IL-6 and increase cell adhesion. ${ }^{46,47}$ Second, in an animal study, increased angiotensin-converting enzyme (ACE) expression has been shown to increase atrial size, leading to increased atrial arrhythmias and angiotensin II, the main active molecule of RAAS, has been implicated in atrial fibrosis and remodelling. ${ }^{39,44,48}$ Finally, atrial tissue from AF patients has been found to have increased ACE signalling, further implicating the RAAS in the development of atrial fibrosis.
Of clinical significance, ACE-inhibitor treatment has been found to reduce atrial remodelling in AF and has been applied therapeutically to reduce AF in hypertensive and heart failure patients. ${ }^{49-52}$

\section{Medical Attention}

Patients with CKD spend more time in direct contact with healthcare professionals than healthy people of a similar age. This is particularly marked for those receiving haemodialysis or awaiting renal transplantation.

Arrhythmias in this group should be diagnosed promptly and referred appropriately. Dialysis gives an exceptional opportunity to observe the heart rhythm under conditions of haemodynamic stress; effectively, it is a twice-weekly provocation test for a large cohort of vulnerable patients.

Cardiac arrest during haemodialysis occurs at a rate of $1-7.5$ per 100,000 haemodialysis sessions, so there is an opportunity to intervene and save lives ${ }^{5-55}$ Dialysis services are therefore obliged to maintain vigilance and preparedness.

\section{Causality}

With so many mechanisms to choose from, the difficulty lies not in determining whether an association exists between CKD and arrhythmias but in determining the most important mechanisms of connection.

A recent bidirectional Mendelian randomisation study attempted to determine the causality involved in the relationship between CKD and AF. The analysis by Park et al. suggested that genetically predicted AF was significantly associated with CKD and a lower estimated glomerular filtration rate (eGFR) with statistically significant causal estimates. They did not detect an effect of genetically determined eGFR on the incidence of AF. This indicated that AF was possibly a causal risk factor for CKD, but not vice versa. ${ }^{56}$ It is unlikely that $A F$ is a direct cause of CKD; the relationship is likely to be more complex and involve a multitude of mechanisms. However, this study does suggest that there is a link between arrhythmias and CKD.

\section{Managing Arrhythmia in Renal Disease}

Management of arrhythmia begins with the accumulation of diagnostic information. The critical step is to collect electrocardiographic documentation at the right moment.

The symptoms of arrhythmia are protean: palpitations, syncope, presyncope and chest discomfort may occur in any form of tachyarrhythmia and in any bradyarrhythmia. ${ }^{57}$ More often, arrhythmias produce just a decline in exercise tolerance, dyspnoea on exertion and general malaise.

Because most arrhythmias are intermittent at their onset, documentation and therefore diagnosis are a challenge. Provided the physician is alert to the possibility of an arrhythmia, electronic devices are available to suit the clinical situation.

The choice of device depends on the frequency and duration of the symptomatic events. Frequent but brief symptoms can be assessed on a 24-hour recording; infrequent events of long duration can be documented by performing a standard ECG when the symptoms are present. Symptoms that are both brief and infrequent may require the implantation of a loop recorder. $^{57}$

Therapy for a patient with arrhythmia should initially address any modifiable underlying condition and should mitigate the risks associated 
Figure 2: Complexity of Device Implantation
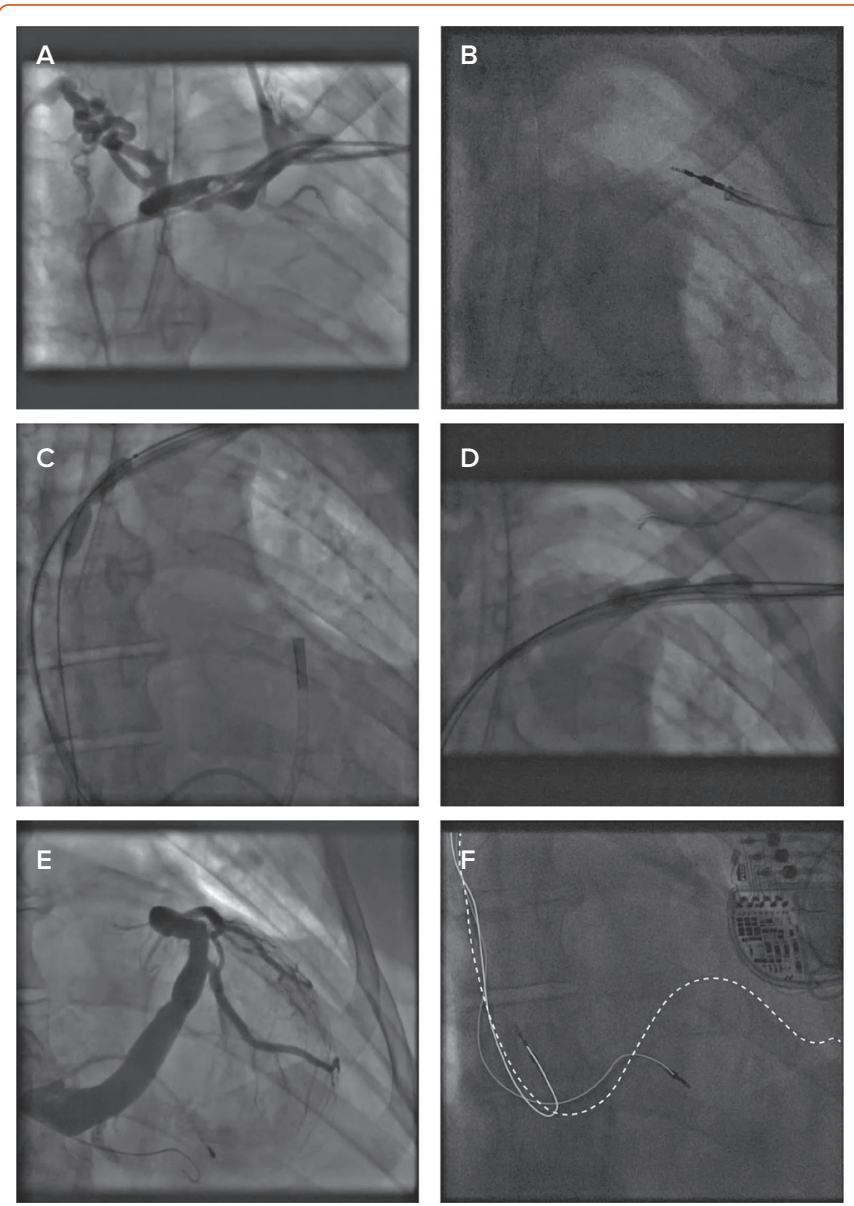

An example of complex device implantation in a patient with chronic kidney disease that illustrates the difficulties involved. There is venous stenosis occlusion at the brachiocephalic vein (A) requiring transvenous lead extraction (B) followed by venous angioplasty (C and D) to create space for the cardiac resynchronisation therapy (E and F).

with the arrhythmia. In all cases, valve disease and myocardial ischaemia should be evaluated and, in general, corrected. Heart failure, if present, should be managed optimally. For the renal patient, correction of underlying causes should include optimisation of the control of renal indices. Mitigation of risks includes rate-limiting therapy for any atrial arrhythmia that of >100 BPM and long-term anticoagulation for many patients with persistent atrial tachyarrhythmias.

With underlying conditions corrected, management of renal problems optimised and the risks of thromboembolic complications mitigated, many patients will experience a resolution of arrhythmia episodes or a resolution of arrhythmia-related symptoms and will not require additional therapy.

For those who experience recurrent or continuing symptomatic episodes, specific therapy is indicated to restore and maintain sinus rhythm. This may involve catheter-based procedures, implanted devices, arrhythmia surgery or specific antiarrhythmic drugs alone or in combination.

\section{Exceptions in Renal Failure}

Patients with renal impairment are vulnerable to complications that make their management diverge in important ways from the general population.

\section{Device Therapy in Chronic Kidney Disease}

Patients with CKD are difficult subjects for device therapy because of the effects of renal replacement therapy on the venous system (Figure 2).
Figure 3: ICD Extraction after Infection in Patient with Renal Failure

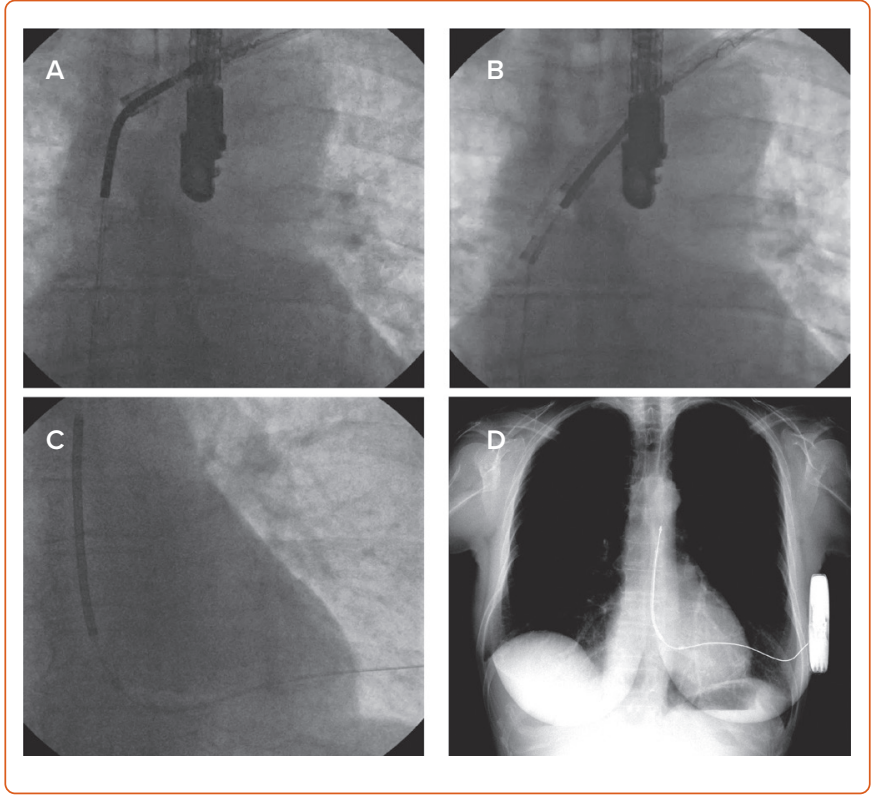

These images show the extraction of an ICD in a patient with renal failure who developed lead-related infection 18 years after implantation of a single-chamber device. The lead was removed using a rotational sheath (A and B). After the patient completed a course of antibiotics, an entirely subcutaneous device was implanted (C), with a chest $X$-ray confirming the position (D).

Chronically indwelling catheters commonly cause venous stenosis or occlusion, making those veins difficult or impossible for subsequent lead implantation.

There are important differences between the general population and the CKD population in the risk associated with device therapy, predominantly due to the risk of device infection.

Infection by bacteria introduced during the implantation procedure can manifest as pocket swelling or erosion of the device through the skin at months or years after implantation. More seriously, endovascular infection can result from bacteria introduced at the time of implantation or from bacteria that colonise the leads, often following introduction during dialysis. Once established, either form of infection is near impossible to control without extraction of the device, a substantial undertaking associated with a mortality risk above $0.2 \%$ even in the most experienced centres (Figure 3).

The risk of infective complication is significantly higher in patients with renal impairment than in the general population; infection is the second leading cause of death in this cohort. ${ }^{58} \mathrm{~A}$ large observational study of 25,675 pre-dialysis patients found that this risk was inversely related to eGFR; the highest risk is associated with the lowest eGFR, with a 3.5-fold higher risk in patients with an eGFR of $30 \mathrm{ml} / \mathrm{min} / 1.73 \mathrm{~m}^{2} .{ }^{59}$

The picture is bleaker for patients on dialysis. The HEMO study, a randomised controlled trial involving 1,846 patients, examined the effects of dialysis dose and flux on patient outcomes found that the there was a $35 \%$ annual hospitalisation rate for infection in this group. The risk of infection-related mortality was also found to be high in this subgroup; $23.1 \%$ of all deaths in this study were infection related whilst $58 \%$ of patients with infection-related first hospitalisation were associated with a severe outcome (death, intensive care stay or prolonged hospital admission). ${ }^{60}$ 
Figure 4: Extraction of a Pacemaker in a Patient with Dialysis-dependent Chronic Kidney Disease

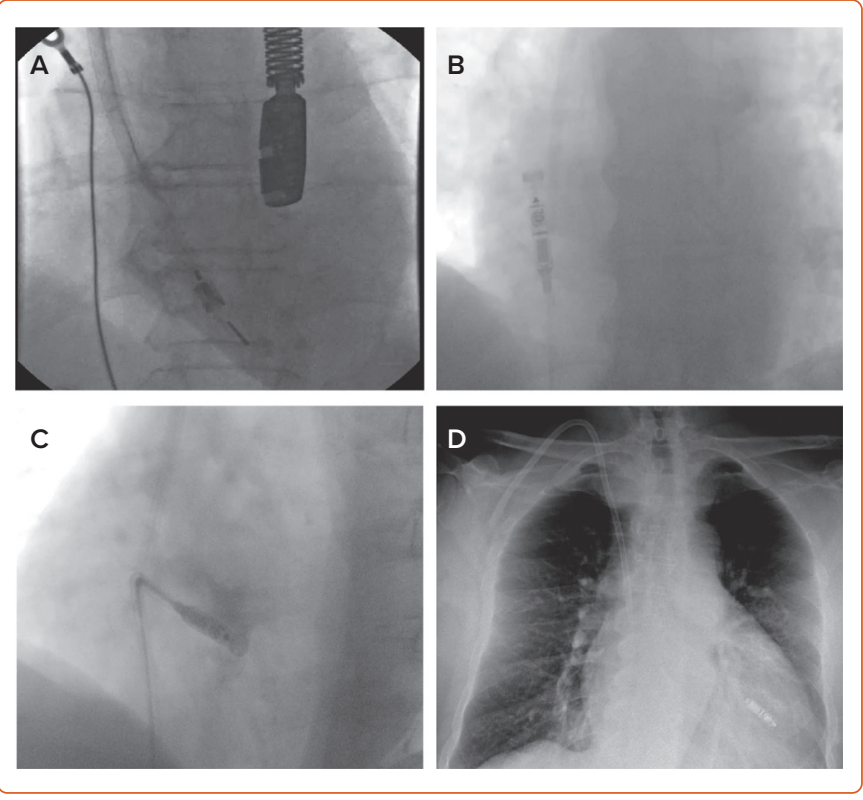

A: A rotational dissecting sheath was used to dissect the pacing lead. B and C: A leadless pacemaker is implanted via the right femoral vein at the right ventricle septum. D: A postprocedure chest radiograph shows a leadless pacemaker in the right ventricle.

Renal impairment has been identified as a potent risk factor for infection in patients with cardiac implantable electronic devices. ${ }^{61}$ For a patient with CKD, the risk of death from device infection is approximately three times higher, enough to influence the risk-benefit calculation that drives decision-making in device therapy. ${ }^{62}$ Many rules of thumb used in the general population are therefore not valid in CKD.

ICD therapy is widely used in patients assessed to have a risk of sudden death of $>1 \%$ per year. Patients with severe impairment of LV systolic function without a reversible cause generally fit this criterion and receive ICD therapy. This is based on the findings of major clinical trials that have demonstrated clear benefit in this cohort of patients. ${ }^{63-65}$

In CKD, the evidence is much less clear; the major ICD trials routinely excluded patients with CKD and the conclusions may therefore not apply to this subgroup. Early evidence suggests that ICD therapy does not benefit patients with loss of kidney function. A retrospective analysis of 61 patients with CKD recruited in MADIT-II did suggest a survival benefit with ICD therapy in patients with an eGFR of $>35 \mathrm{ml} / \mathrm{min} / \mathrm{m}^{2}$; however, there was no benefit in patients with an eGFR of $<35 \mathrm{ml} / \mathrm{min} / \mathrm{m}^{2}$.

There is evidence that CKD increases the risk of death in patients receiving an ICD. An observational study of 507 consecutive patients with varying stages of CKD receiving a novel ICD implant found a risk of mortality with renal impairment that increased stepwise by eGFR stage; renal dysfunction was independently associated with mortality in patients receiving an ICD. ${ }^{66}$

This was validated by subsequent meta-analyses, which concluded that CKD in patients with an ICD significantly increased the risk of mortality and suggested that this risk is comparable between earlier stages of renal insufficiency to end-stage renal disease. ${ }^{67,68}$

A study involving two separate meta-analyses performed by Makki et al. evaluated the effect of CKD on ICD and ICD on CKD patient outcomes. The authors concluded that ICD patients have a higher risk of dying if they have CKD in comparison to those ICD patients who did not have CKD. Conversely, CKD patients have a lower risk of mortality (from SCD) with an ICD, comparatively to those CKD patients who did not have an ICD fitted. ${ }^{69}$

A subsequent randomised controlled trial of 188 patients on dialysis with a left ventricular ejection fraction of $>35 \%$ found that prophylactic ICD therapy did not reduce mortality from sudden cardiac death compared to not receiving this therapy. ${ }^{70}$ Despite this, $13.8 \%$ of the ICD group received appropriate ICD therapy for ventricular arrhythmias and there was an overall lower incidence of SCD (10.1\%) than in previous reports (22-26\%). ${ }^{70}$ There are notable limitations to this trial: the ICD was implanted in patients with no class I indication so the risk of SCD was lower. The population was also well optimised before enrolment, which may have protected against SCD.

The classification of SCD is difficult, especially in the absence of any cardiac monitoring during the terminal event. It is assumed arrhythmic if the patient's death was sudden, unwitnessed and the patient was well when last observed. Therefore, it is difficult to accurately assess endpoint in the two subgroups. ${ }^{70}$

ICD therapy is, therefore, reserved for those at highest risk of arrhythmiarelated death, including survivors of a cardiac arrest due to ventricular tachycardia or ventricular fibrillation.

When an implanted device is required, the presence of CKD has an important influence on the choice of methodology and equipment. Mitigation of the risk of infection is the key objective; because the greatest modifiable risk is the seeding of bacteria to device surfaces exposed to the vascular space, measures are taken to minimise the exposed surface area.

In the case of ICD therapy, intravascular components can be eliminated completely, using solely components that lie in the subcutaneous space. These devices lack the capability to treat bradycardia that is universal in transvenous devices but, in many cases, the risk of fatal bradyarrhythmia is less than the risk of fatal infection.

Pacing therapy can be delivered through a leadless system (Figure 4); although this lies in the vascular space, it benefits from having a surface area far less than that of a pacing lead.

\section{Procedural Risks and Benefits of Ablation}

Arrhythmias are very managed definitively by catheter-based procedures. Circuits are destroyed by radiofrequency (RF) energy, pulsed field energy, laser or cryotherapy delivered by catheters placed via the femoral vessels or, less often, epicardially.

For most symptomatic and recurrent arrhythmias, catheter ablation is the accepted firstline therapy. Catheter ablation has become one of the most common medical procedures, with most of these performed for AF.

Ablation for AF in patients with CKD carries a greater risk than for other patients, including a risk of acute exacerbation of renal dysfunction, but there is evidence that the procedure can result in improved renal function over the long term. ${ }^{71}$

A prospective study of 386 patients who underwent AF ablation revealed that eGFR improved with restoration of sinus rhythm within 3 months of the procedure and was maintained up to 1 year after the ablation. Patients 
Figure 5: Deterioration in Renal Function Seen After AF Ablation
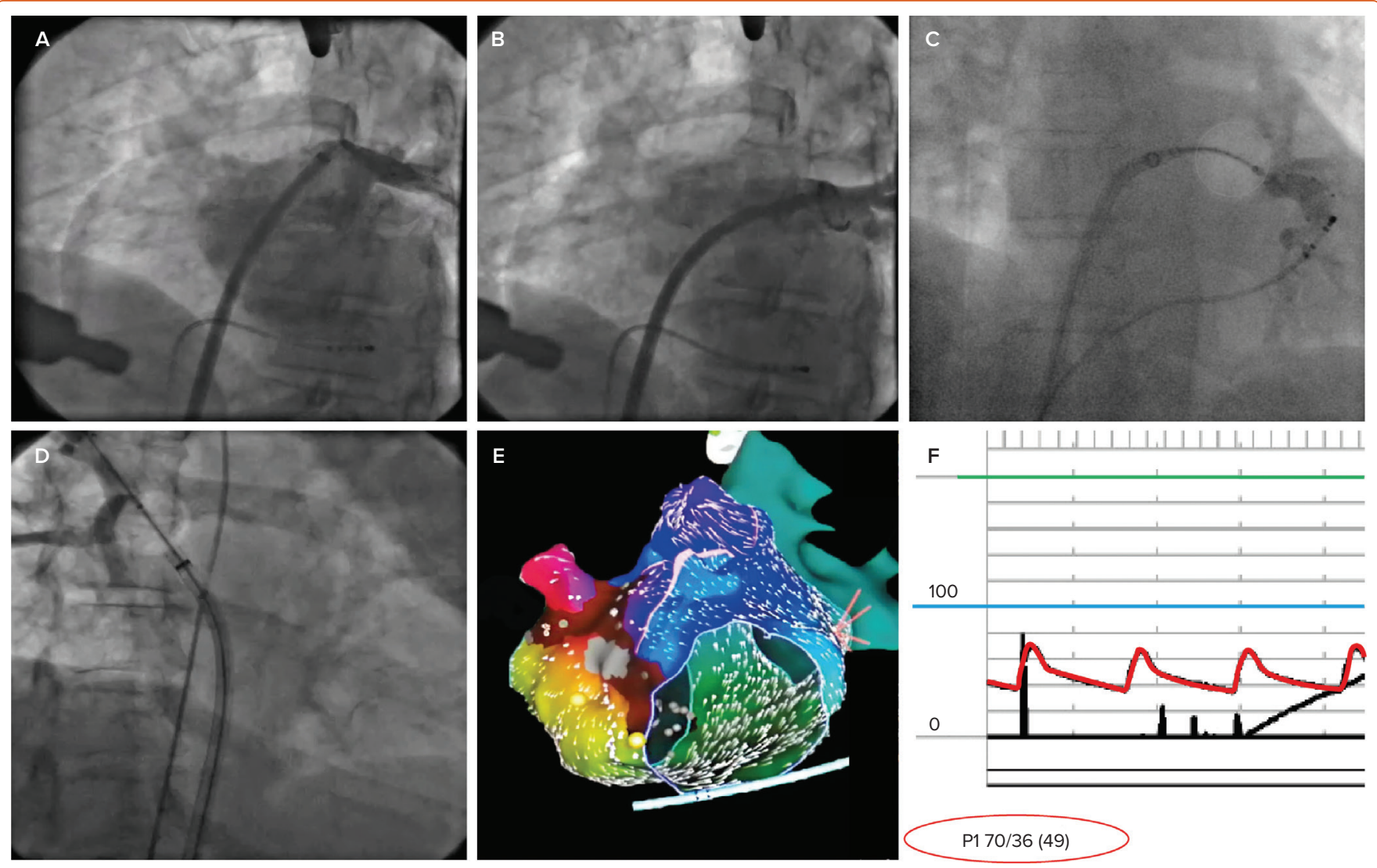

Examples of ablation for AF illustrating the mechanisms for the post-procedure deterioration in renal function seen in some cases. A and B: Ablation in the manner originally involved X-ray based catheter manipulation and therefore required imaging of the veins by injection of contrast agents. C and D: a more recent innovation, the cryoballoon, is also guided radiologically and contrast agents are generally used. E: most radiofrequency ablation now involves the use of a 3D mapping system, which eliminates the need for contrast. F: because the mapping system is vulnerable to disruption by patient movement, these procedures are usually performed under general anaesthesia or deep sedation, which makes the patient vulnerable to periods of hypotension during the procedure.

with arrhythmia recurrence demonstrated a reduction in the renal function. ${ }^{72}$

Recurrence following AF ablation is not uncommon in patients with CKD. In a study of 221 patients with a mean follow-up of 32 months following AF ablation therapy, CKD patients had a significantly higher incidence of AF recurrence than non-CKD participants; CKD was identified as independent associated variate with $\mathrm{AF}$ recurrence. ${ }^{73}$

This is consistent with a recent meta-analysis of seven observational studies, which concluded that CKD was significantly associated with higher AF recurrence than in to non-CKD patients (OR 3.71)..$^{74}$

The kidneys are vulnerable to injury from use of radiological contrast media. Early methods of RF ablation for AF necessitated the use of contrast. ${ }^{75}$ Current RF methods rely on 3D mapping systems, which obviate the need for this medium (Figure 5) but create a need for general anaesthesia or deep sedation combined with analgesia, which can create hypotension severe enough to injure the kidneys.

Cryotherapy is comparable in efficacy to RF methods, but usually involves the use of contrast agents. ${ }^{76}$ RF ablation without contrast and with meticulous control of arterial pressure is the preferred method.

\section{Pharmacokinetics}

Antiarrhythmic drug therapy with agents that modify the function of ion channels can be used selectively in the management of certain arrhythmias, usually as a bridging measure until an underlying condition is corrected or definitive therapy can be offered. This group of drugs has been shown to increase all-cause mortality in a number of studies in different patient populations, so their long-term use as the sole management strategy has diminished..$^{77-79}$

There are insufficient data to determine specifically the risks of antiarrhythmic drugs in patients with CKD, but the altered and unpredictable pharmacokinetics of the renal failure state would be expected to augment the risk.

Because these medications act on sodium and potassium channels, the exaggerated fluctuations in ion concentration associated with CKD and dialysis could also pose a risk.

Even $\beta$-blocking drugs - a group associated with few dangerous adverse effects in the general population - can cause serious adverse effects in the context of CKD, where altered kinetics combined with electrolyte disturbance can trigger BRASH syndrome.

\section{Bleeding}

Bleeding complications are much more common in CKD, and are probably an effect of platelet dysfunction combined with the consequences of hypertension and direct vascular effects.

Bleeding complications occurring at the time of device implantation or ablation account for some of the excess risks of these therapies in CKD 
Figure 6: Cardiac Problems and Treatments in Chronic Kidney Disease

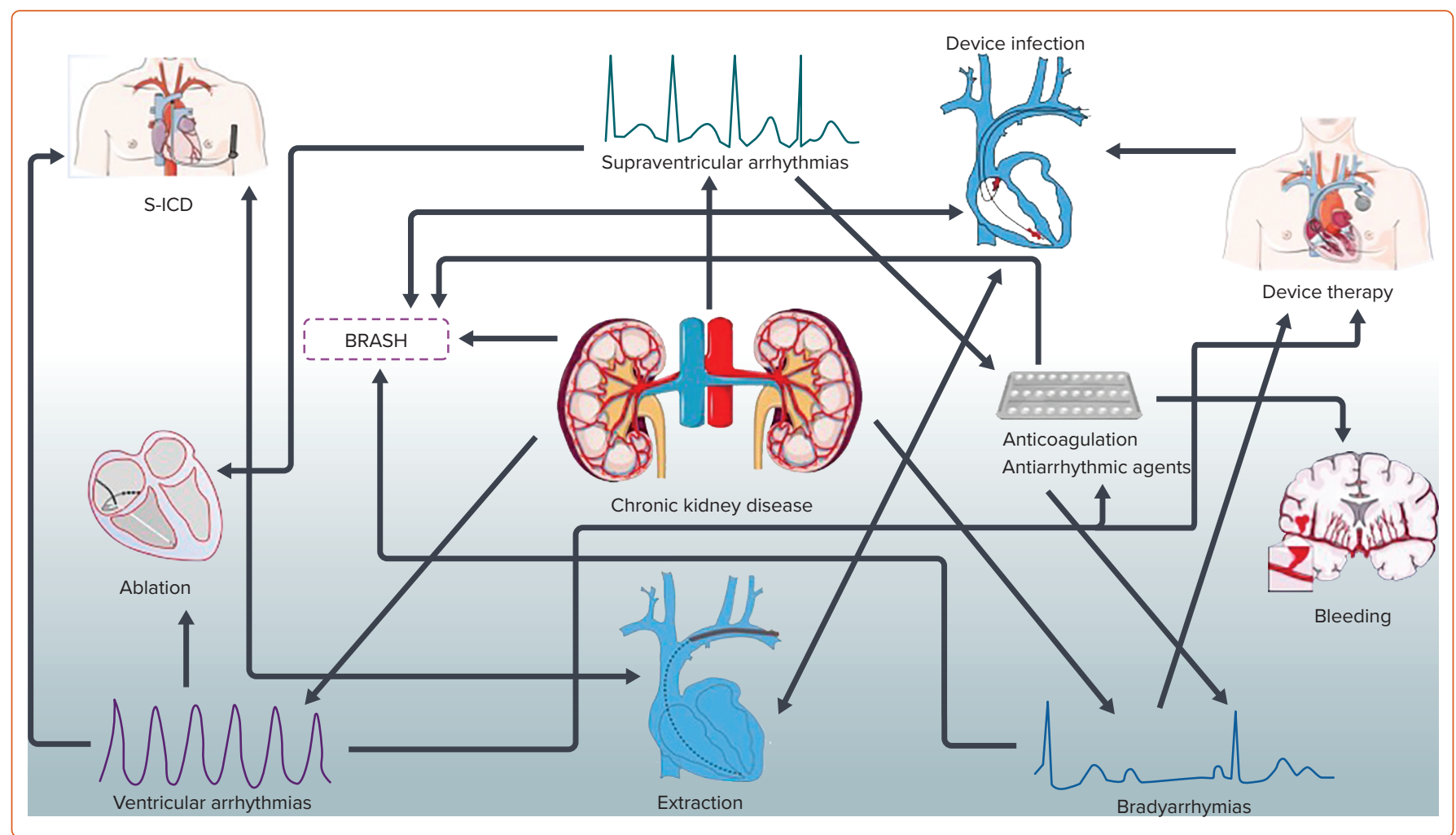

This flow diagram depicts the arrhythmias, treatment and potential complications associated with chronic kidney disease. BRASH = bradycardia, renal failure, atrioventricular block, shock and hyperkalaemia; $S$ - $I C D=$ subcutaneous $I C D$.

patients. ${ }^{80}$ The risk of spontaneous bleeding, most importantly intracranial bleeding, is high enough to move the balance of risk associated with the use of long-term anticoagulants.

In the general population, AF combined with one other risk for thromboembolism creates a risk that is great enough to justify the haemorrhagic risk of long-term anticoagulation for most patients. In patients with CKD, the increased risk of bleeding is sufficient to outweigh the risk of thromboembolism such that anticoagulation is reserved for those at highest risk of thromboembolism.

When anticoagulants are required, choice is restricted in the CKD population. Warfarin and other vitamin-K antagonists have been almost entirely displaced by direct oral anticoagulant (DOAC) drugs in the general population,based partly on evidence of a safety benefit but mostly due to the inconvenience of the blood testing required to make vitamin-K antagonists safe. ${ }^{81-84}$

These agents rely on renal clearance and so their application in patients with CKD has limitations. In general, patients with a creatinine clearance ( $\mathrm{CrCl}$ ) of $<50 \mathrm{ml} / \mathrm{min}$ have been recommended to lower the dose of their DOAC, while those with a $\mathrm{CrCl}$ clearance of $<15 \mathrm{ml} / \mathrm{min}$ are advised against their use ${ }^{85}$ Despite this dose reduction in moderate renal impairment $(\mathrm{CrCl}$ $30-50 \mathrm{ml} / \mathrm{min}$ ), DOAC agents have been shown to be safe and efficacious with a comparable bleeding risk and stroke prevention to warfarin. ${ }^{86}$

There is evidence suggesting that they may be safe in severe renal impairment also, with some reassuring experience in patients receiving renal dialysis. ${ }^{87-88}$ A Cochrane review of 12,545 patients assessed the efficacy and safety of DOACs versus warfarin in patients with AF and CKD. Of these, 390 had severe renal impairment $(\mathrm{CrCl} 15-30 \mathrm{ml} / \mathrm{min}){ }^{89}$ In keeping with previous evidence, the study concluded that DOACs were as safe and efficacious as warfarin.

Although the study applies mostly to patients with moderate renal failure, it also indicated DOAC use in the severe category was plausible and possibly safe; further work is required. On the basis of current evidence, DOAC therapy is not available to most patients with CKD so the inconvenience of warfarin and similar agents is an added reason to avoid anticoagulation.

Left atrial appendage occlusion, by a catheter-based procedure or removal or occlusion of the appendage by minimally invasive surgery, has the potential to resolve the dilemma of stroke risk and bleeding risk in CKD patients. These interventions have been shown to have a similar efficacy to anticoagulation in preventing stroke in the general $A F$ population, and the catheter-based approach compares favourably to either anticoagulation or no therapy in dialysis patients. ${ }^{90}$

\section{Economic Impact of Arrhythmias in CKD}

The economic impact of AF in CKD is difficult to quantify as it is a cumulative effect. Catheter ablation is expensive, although the costs are improving.

A study based on a registry of 12,027 patients found that catheter ablation was relatively expensive, with first procedure success associated with a significantly lower cost than repeat ablations. ${ }^{91}$ As the likelihood of arrhythmia recurrence is higher in CKD patients, this is significant.

In comparison to pharmacotherapy, however, catheter ablation is an economically viable option. A cost-effectiveness systematic analysis comparing catheter ablation with pharmacotherapy for $\mathrm{AF}$ revealed that ablation therapy in the medium-to-long term was more cost-effective than 
medical therapy. ${ }^{92}$ This is probably influenced by the number of repeated hospital admissions associated with arrhythmias managed with pharmacological agents as well as the overall cost of these agents over the lifetime of a patient.

In patients with CKD, medical therapy with anti-arrhythmic agents is also difficult because of the side effects associated with them; the majority have proarrhythmic effects and the metabolic imbalances in CKD are likely to compound this further.

Cardiac rhythm management with device therapy also has upfront costs. In the heart failure patient, device therapy requires careful consideration of benefit and cost. In the CKD population, this is amplified as this cohort has an overall lower life expectancy than the general population. ${ }^{93}$
The evidence of benefit is also not as clear. There are additional risks to consider, including device infection and consequent treatments including transvenous lead extractions (Figure 6), which are costly. Leadless systems are increasingly prevalent and, although they carry a smaller risk of transvenous infections, they are far more expensive. ${ }^{94}$

\section{Conclusion}

Patients with CKD are vulnerable to arrhythmia for many reasons that are well understood and probably through other less familiar mechanisms. Management of arrhythmia is made more difficult by the presence of severe renal dysfunction, but therapeutic options are available and continue to evolve. Optimal management of arrhythmia not only improves the quality of life of many patients but can, in some cases, extend life and slow the progression of CKD. $\square$
1. Krijthe BP, Kunst A, Benjamin EJ, et al. Projections on the number of individuals with atrial fibrillation in the European Union, from 2000 to 2060. Eur Heart J 2013;34:2746-51. https://doi.org/10.1093/eurheartj/eht280; PMID: 23900699.

2. GBD 2017 Disease and Injury Incidence and Prevalence Collaborators. Global, regional, and national incidence, prevalence, and years lived with disability for 354 diseases and injuries for 195 countries and territories, 1990-2017: a systematic analysis for the Global Burden of Disease Study 2017. Lancet 2018;392:1789-858. https://doi.org/10.1016/ S0140-6736(18)32279-7; PMID: 30496104

3. Chiu DYY, Sinha S, Kalra PA, Green D. Sudden cardiac death in haemodialysis patients: preventative options. Nephrol (Carlton) 2014:19:740-9. https://doi.org/10.1111/nep.12337. PMID: 25231407.

4. Kim ED, Soliman EZ, Coresh J, et al. Two-week burden of arrhythmias across CKD severity in a large communitybased cohort: the ARIC study. J Am Soc Nephrol 2021;32:629-38. https://doi.org/10.1681/ASN.2020030301; PMID: 33510037.

5. Rautavaara J, Kerola T, Kaartinen K, et al. Asystole episodes and bradycardia in patients with end-stage renal disease. Nephrol Dial Transplant 2022;37:575-83, https://doi. org/10.1093/ndt/gfab023; PMID: 33527131

6. Pisani A, Visciano B, Imbriaco M, et al. The kidney in Fabry's disease. Clin Genet 2014;86:301-9. https://doi.org/10.1111/ cge.12386; PMID: 24645664

7. Alroy J, Sabnis S, Kopp JB. Renal pathology in Fabry disease. J Am Soc Nephrol 2002;13(Suppl 2):S134-8. https:// doi.org/10.1097/01.ASN.0000016684.07368.75; PMID: 12068025.

8. Jaurretche S, Antogiovanni N, Perretta F. Prevalence of chronic kidney disease in fabry disease patients: multicente cross sectional study in Argentina. Mol Genet Metab Rep 2017;12:41-3. https://doi.org/10.1016/j.ymgmr.2017.05.007; PMID: 28607873

9. Shah JS, Hughes DA, Sachdev B, et al. Prevalence and clinical significance of cardiac arrhythmia in Anderson-Fabry disease. Am J Cardiol 2005;96:842-6. https://doi. org/10.1016/j.amjcard.2005.05.033; PMID: 16169374.

10. Acharya D, Robertson P, Neal Kay G, et al. Arrhythmias in Fabry cardiomyopathy. Clin Cardiol 2012;35:738-40. https:// doi.org/10.1002/clc.22047; PMID: 22886820.

11. Gulati A, Jabbour A, Ismail TF, et al. Association of fibrosis with mortality and sudden cardiac death in patients with nonischemic dilated cardiomyopathy. JAMA 2013;309:896908. https://doi.org/10.1001/jama.2013.1363. PMID: 23462786 .

12. Turakhia MP, Blankestijn PJ, Carrero JJ, et al. Chronic kidney disease and arrhythmias: conclusions from a Kidney Disease: Improving Global Outcomes (KDIGO) Controversies Conference. Eur Heart J 2018;39:2314-25. https://doi. org/10.1093/eurheartj/ehy060; PMID: 29522134

13. Baig S, Edward NC, Kotecha D, et al. Ventricular arrhythmia and sudden cardiac death in Fabry disease: a systematic review of risk factors in clinical practice. Europace 2018;20:f153-61. https://doi.org/10.1093/europace/eux261; PMID: 29045633

14. Tang W, McDonald SP, Hawley CM, et al. End-stage renal failure due to amyloidosis: outcomes in 490 ANZDATA registry cases. Nephrol Dial Transplant 2013;28:455-61. https://doi.org/10.1093/ndt/gfs492; PMID: 23182810.

15. Shah KB, Inoue Y, Mehra MR. Amyloidosis and the heart: a comprehensive review. Arch Intern Med 2006;166:1805-13. https://doi.org/101001/archinte166.17.1805; PMID: 17000935.

16. Giancaterino S, Urey MA, Darden D, Hsu JC. Management of arrhythmias in cardiac amyloidosis. JACC Clin Electrophysiol 2020;6:351-61. https://doi.org/10.1016/j.jacep.2020.01.004 PMID: 32327068 .

17. Barbhaiya CR, Kumar S, Baldinger $\mathrm{SH}$, et al. Electrophysiologic assessment of conduction abnormalities and atrial arrhythmias associated with amyloid cardiomyopathy. Heart Rhythm 2016;13:383-90. https://doi. org/10.1016/j.hrthm.2015.09.016; PMID: 26400855.

18. Staron A, Zheng L, Doros $G$, et al. Marked progress in AL amyloidosis survival: a 40-year longitudinal natural history study. Blood Cancer J 2021;11:139. https://doi.org/10.1038/ s41408-021-00529-w; PMID: 34349108.

19. Staude H, Jeske S, Schmitz K, et al. Cardiovascular risk and mineral bone disorder in patients with chronic kidney disease. Kidney Blood Press Res 2013;37:68-83. https://doi. org/10.1159/000343402; PMID: 23548827

20. Mirza MAl, Larsson A, Melhus H, et al. Serum intact FGF23 associate with left ventricular mass, hypertrophy and geometry in an elderly population. Atherosclerosis 2009;207:546-51. https://doi.org/10.1016/j. atherosclerosis.2009.05.013; PMID: 19524924

21. Laukkanen JA, Khan $\mathrm{H}$, Kurl S, et al. Left ventricular mass and the risk of sudden cardiac death: a population-based study. J Am Heart Assoc 2014;3:e001285. https://doi. org/10.1161/JAHA.114.001285; PMID: 25376188

22. Inaba M, Okuno S, Imanishi Y, et al. Role of fibroblast growth factor-23 in peripheral vascular calcification in nondiabetic and diabetic hemodialysis patients. Osteoporos Int 2006;17:1506-13. https://doi.org/10.1007/s00198-006-01546; PMID: 16896512

23. Srivaths PR, Goldstein SL, Silverstein DM, et al. Elevated FGF 23 and phosphorus are associated with coronary calcification in hemodialysis patients. Pediatr Nephrol 2011;26:945-51. https://doi.org/10.1007/s00467-011-1822-0; PMID: 21359960

24. Park CW, Oh YS, Shin YS, et al. Intravenous calcitriol regresses myocardial hypertrophy in hemodialysis patients with secondary hyperparathyroidism. Am J Kidney Dis 1999;33:73-81. https://doi.org/10.1016/S02726386(99)70260-X; PMID: 9915270.

25. Thorp ML, Johnson ES, Yang X, et al. Effect of anaemia on mortality, cardiovascular hospitalizations and end-stage renal disease among patients with chronic kidney disease. Nephrology 2009;14:240-6. https://doi. org/10.1111/j.1440-1797.2008.01065.x; PMID: 19207866

26. Martinez-Vea A, Marcas L, Bardají A, et al. Role of oxidative stress in cardiovascular effects of anemia treatment with erythropoietin in predialysis patients with chronic kidney disease. Clin Nephrol 2012;77:171-81. https://doi.org/10.5414/ CN107309; PMID: 22377247.

27. Drüeke TB, Locatelli $F$, Clyne $N$, et al. Normalization of hemoglobin level in patients with chronic kidney disease and anemia. N Engl J Med 2006;355:2071-84. https://doi. org/10.1056/NEJMoa062276; PMID: 17108342.

28. Singh AK, Szczech L, Tang KL, et al. Correction of anemia with epoetin alfa in chronic kidney disease. $N$ Eng/ J Med 2006;355:2085-98. https://doi.org/10.1056/NEJMoa065485; PMID: 17108343.

29. Schüttler D, Schönermarck U, Wenner F, et al. Large potassium shifts during dialysis enhance cardiac repolarization instability. J Nephrol 2021;34:1301-5. https:// doi.org/10.1007/s40620-020-00880-4; PMID: 33058038

30. Weiss JN, Qu Z, Shivkumar K. Electrophysiology of hypokalemia and hyperkalemia. Circ Arrhythm Electrophysiol. 2017;10:e004667. https://doi.org/10.1161/CIRCEP.116.004667; PMID: 28314851.
31. Farkas JD, Long B, Koyfman A, Menson K. BRASH syndrome: bradycardia, renal failure, AV blockade, shock, and hyperkalemia. J Emerg Med 2020;59:216-23. https://doi org/10.1016/i.jemermed.2020.05.001; PMID: 32565167.

32. Orlov S, Cherney DZI, Pop-Busui R, et al. Cardiac autonomic neuropathy and early progressive renal decline in patients with nonmacroalbuminuric type 1 diabetes. Clin J Am Soc Nephro/ 2015;10:1136-44. https://doi.org/10.2215/ CJN.11441114; PMID: 26092828.

33. Schlaich MP, Socratous F, Hennebry S, et al. Sympathetic activation in chronic renal failure. J Am Soc Nephrol 2009;20:933-9. https://doi.org/10.1681/ASN.2008040402; PMID: 18799718.

34. Esler M. The autonomic nervous system and cardiac arrhythmias. Clin Auton Res 1992;2:133-5. https://doi. org/10.1007/BF01819669; PMID: 1638108

35. Baber U, Howard VJ, Halperin JL, et al. Association of chronic kidney disease with atrial fibrillation among adults in the United States: REasons for Geographic and Racial Differences in Stroke (REGARDS) study. Circ Arrhythm Electrophysiol 2011;4:26-32. https://doi.org/10.1161/ CIRCEP.110.957100; PMID: 21076159.

36. Yu L, Huang B, Wang Z, et al. Impacts of renal sympathetic activation on atrial fibrillation: the potential role of the autonomic cross talk between kidney and heart. J Am Heart Assoc 2017;6:e004716. https://doi.org/10.1161/ JAHA.116.004716; PMID: 28255078

37. Pokushalov E, Romanov A, Corbucci G, et al. A randomized comparison of pulmonary vein isolation with versus without concomitant renal artery denervation in patients with refractory symptomatic atrial fibrillation and resistant hypertension. J Am Coll Cardio/ 2012;60:1163-70. https://doi. org/10.1016/j.jacc.2012.05.036; PMID: 22958958.

38. Yao C, Veleva T, Scott L, et al. Enhanced cardiomyocyte NLRP3 inflammasome signaling promotes atrial fibrillation. Circulation 2018;138:2227-42. https://doi.org/10.1161/ CIRCULATIONAHA.118.035202: PMID: 29802206.

39. Xintarakou A, Tzeis S, Psarras S, et al. Atrial fibrosis as a dominant factor for the development of atrial fibrillation: facts and gaps. Europace 2020;22:342-51. https://doi. org/10.1093/europace/euaa009; PMID: 31998939.

40. Vilaysane A, Chun J, Seamone ME, et al. The NLRP3 inflammasome promotes renal inflammation and contributes to CKD. J Am Soc Nephrol JASN 2010;211732-44. https://doi. org/10.1681/ASN.2010020143; PMID: 20688930.

41. Chin LH, Hsu YJ, Hsu SC, et al. The regulation of NLRP3 inflammasome expression during the development of cardiac contractile dysfunction in chronic kidney disease. Oncotarget 2017;8:113303-17. https://doi.org/10.18632/ oncotarget.22964; PMID: 29371912.

42. Yeyati NL, Adrogué HJ. Inappropriately high plasma renin activity accompanies chronic loss of renal function. Am J Nephrol 1996;16:471-7. https://doi.org/10.1159/000169046; PMID: 8955757.

43. Ruiz-Ortega M, Lorenzo O, Suzuki Y, et al. Proinflammatory actions of angiotensins. Curr Opin Nephrol Hypertens 2001;10:321-9. https://doi.org/10.1097/00041552200105000-00005; PMID: 11342793.

44. Xiao HD, Fuchs S, Campbell DJ, et al. Mice with cardiac restricted angiotensin-converting enzyme (ACE) have atria enlargement, cardiac arrhythmia, and sudden death. Am J Pathol 2004:165:1019-32.https://doi.org/10.1016/S00029440(10)63363-9; PMID: 15331425

45. Cao W, Song S, Fang G, et al. Cadherin-11 deficiency attenuates Ang-II-induced atrial fibrosis and susceptibility to atrial fibrillation. J Inflamm Res 2021;14:2897-911. https://doi. 
org/10.2147/JIR.S306073; PMID: 34239314

46. Ishizaka N, Nakao A, Ohishi N et al. Increased leukotriene $A(4)$ hydrolase expression in the heart of angiotensin II-induced hypertensive rat. FEBS Lett 1999;463:155-9. https://doi.org/10.1016/S0014-5793(99)01607-5; PMID: 10601658.

47. Pueyo ME, Gonzalez W, Nicoletti A, et al. Angiotensin I stimulates endothelial vascular cell adhesion molecule-1 via nuclear factor-kappaB activation induced by intracellular oxidative stress. Arterioscler Thromb Vasc Biol 2000;20:64551. https://doi.org/10.1161/01.ATV.20.3.645; PMID: 10712386.

48. Goette A, Staack T, Röcken C, et al. Increased expression of extracellular signal-regulated kinase and angiotensinconverting enzyme in human atria during atrial fibrillation. $J$ Am Coll Cardiol 2000;35:1669-77. https://doi.org/10.1016/ S0735-1097(00)00611-2: PMID: 10807475.

49. Li Y, Li W, Yang B, et al. Effects of cilazapril on atrial electrical, structural and functional remodeling in atria fibrillation dogs. J Electrocardio/ 2007;40:100.e1-6. https:// doi.org/10.1016/j.jelectrocard.2006.04.001; PMID: 17067622

50. Shi Y, Li D, Tardif JC, Nattel S. Enalapril effects on atria remodeling and atrial fibrillation in experimental congestive heart failure. Cardiovasc Res 2002;54:456-61. https://doi. org/10.1016/S0008-6363(02)00243-2; PMID: 12062350.

51. Boldt A, Scholl A, Garbade J, et al. ACE-inhibitor treatment attenuates atrial structural remodeling in patients with lone chronic atrial fibrillation. Basic Res Cardiol 2006;101:261-7. https://doi.org/10.1007/s00395-005-0571-2; PMID: 16382287.

52. Healey JS, Baranchuk A, Crystal E, et al. Prevention of atria fibrillation with angiotensin-converting enzyme inhibitors and angiotensin receptor blockers: a meta-analysis. J Am Coll Cardiol 2005;45:1832-9. https://doi.org/10.1016/j. jacc.2004.11.070; PMID: 15936615.

53. Tanaka T, Nomura Y, Hirama C, et al. Cardiac arrest during hemodialysis: a survey of five Japanese hospitals. Acute Med Surg 2020;7:e476. https://doi.org/10.1002/ams2.476; PMID: 31988788.

54. Karnik JA, Young BS, Lew NL, et al. Cardiac arrest and sudden death in dialysis units. Kidney Int 2001;60:350-7. https://doi.org/10.1046/j.1523-1755.2001.00806.x PMID: 11422771

55. Douvris A, Malhi G, Hiremath S, et al. Interventions to prevent hemodynamic instability during renal replacement therapy in critically ill patients: a systematic review. Crit Care 2018;22:41. https://doi.org/10.1186/s13054-018-1965-5; PMID: 29467008

56. Park S, Lee S, Kim Y, et al. Atrial fibrillation and kidney function: a bidirectional Mendelian randomization study. Eur Heart J 2021;42:2816-23. https://doi.org/10.1093/eurheartj/ ehab291; PMID: 34023889

57. El Hage N, Jaar BG, Cheng A, et al. Frequency of arrhythmia symptoms and acceptability of implantable cardiac monitors in hemodialysis patients. BMC Nephro/ 2017:1:309. https://do org/10.1186/s12882-017-0740-1; PMID: 29017465.

58. Dalrymple LS, Go AS. Epidemiology of acute infections among patients with chronic kidney disease. Clin J Am Soc Nephrol 2008:3:1487-93. https://doi.org/10.2215/ CJN.01290308; PMID: 18650409

59. James MT. Risk of bloodstream infection in patients with chronic kidney disease not treated with dialysis. Arch Intern Med 2008;168:2333. https://doi.org/10.1001/ archinte 168.21.2333: PMID: 19029498

60. Allon M, Depner TA, Radeva M, et al. Impact of dialysis dose and membrane on infection-related hospitalization and death: results of the HEMO study. J Am Soc Nephrol 2003;14:1863-70. https://doi.org/10.1097/01 ASN.000007423778764.D1: PMID: 12819247

61. Bloom H, Heeke B, Leon A, et al. Renal insufficiency and the risk of infection from pacemaker or defibrillator surgery. Pacing Clin Electrophysio/ 2006;29:142-5. https://doi. org/10.1111/j.1540-8159.2006.00307.x; PMID: 16492298.

62. Baman TS, Gupta SK, Valle JA, Yamada E. Risk factors for mortality in patients with cardiac device-related infection Circ Arrhythm Electrophysiol 2009;2:129-34. https://doi. org/10.1161/CIRCEP108.816868; PMID: 19808457.
63. Moss AJ, Hall WJ, Cannom DS, et al. Improved survival with an implanted defibrillator in patients with coronary disease at high risk for ventricular arrhythmia. $N$ Engl J Med 1996;335:1933-40. https://doi.org/10.1056/ NEJM199612263352601; PMID: 8960472

64. Moss AJ, Zareba W, Hall WJ, et al. Prophylactic implantation of a defibrillator in patients with myocardial infarction and reduced ejection fraction. N Engl J Med 2002;346:877-83. https://doi.org/10.1056/Nejmoa013474; PMID: 11907286.

65. Bardy GH, Lee KL, Mark DB, et al. Amiodarone or an implantable cardioverter-defibrillator for congestive heart failure. N Engl J Med 2005;352:225-37. https://doi. org/10.1056/NEJMoa043399; PMID: 15659722.

66. Turakhia MP, Varosy PD, Lee K, et al. Impact of renal function on survival in patients with implantable cardioverter-defibrillators. Pacing Clin Electrophysiol 200;30:377-84. https://doi org/10.1111/j.1540-8159.2007.00678.x; PMID: 17367357.

67. Sakhuja R, Keebler M, Lai T-S, et al. Meta-analysis of mortality in dialysis patients with an implantable cardioverter defibrillator. Am J Cardiol 2009:103·735-41. https://doi.org/10.1016/j.amjcard.2008.11.014; PMID: 19231344

68. Korantzopoulos P, Liu T, Li L, et al. Implantable cardioverte defibrillator therapy in chronic kidney disease: a metaanalysis. Europace 2009;11:1469-75. https://doi.org/10.1093 europace/eup282; PMID: 19812050

69. Makki N, Swaminathan PD, Hanmer J, Olshansky B. Do implantable cardioverter defibrillators improve survival in patients with chronic kidney disease at high risk of sudden cardiac death? A meta-analysis of observational studies. Europace 2014;16:55-62. https://doi.org/10.1093/europace/ eut277; PMID: 24058182

70. Jukema JW, Timal RJ, Rotmans JI, et al. Prophylactic use of implantable cardioverter-defibrillators in the prevention of sudden cardiac death in dialysis patients. Circulation 2019;139:2628-38. https://doi.org/10.1161 CIRCULATIONAHA.119.039818; PMID: 30882234

71. Okawa K, Miyoshi T, Sogo M, et al. Improvement in renal and endothelial function after catheter ablation in patients with persistent atrial fibrillation. J Cardio/ 2020:76:610-7. https://doi.org/10.1016/j.jjcc.2020.07.002; PMID: 32682629

72. Takahashi Y, Takahashi A, Kuwahara T, et al. Renal function after catheter ablation of atrial fibrillation. Circulation 2011;124:2380-7. https://doi.org/10.1161/ CIRCULATIONAHA.111.047266; PMID: 22042886.

73. Naruse Y, Tada H, Sekiguchi Y, et al. Concomitant chronic kidney disease increases the recurrence of atrial fibrillation after catheter ablation of atrial fibrillation: a mid-term followup. Heart Rhythm 2011;8:335-41. https://doi.org/10.1016/j. hrthm.2010.10.047; PMID: 21056121

74. Lee W, Wu P, Fang C, et al. Impact of chronic kidney disease on atrial fibrillation recurrence following radiofrequency and cryoballoon ablation: a meta-analysis. Int J Clin Pract. 2021;75:e14173. https://doi.org/10.1111/ijcp.14173; PMID: 33756030

75. Haïssaguerre M, Jaïs P, Shah DC, et al. Spontaneous initiation of atrial fibrillation by ectopic beats originating in the pulmonary veins. N Engl J Med 1998:339:659-66. https doi.org/10.1056/NEJM199809033391003; PMID: 9725923.

76. Gallagher MM, Yi G, Gonna H, et al. Multi-catheter cryotherapy compared with radiofrequency ablation in longstanding persistent atrial fibrillation: a randomized clinical trial. Europace 2021;23:370-9. https://doi.org/10.1093/ europace/euaa289; PMID: 33188692

77. Cardiac Arrhythmia Suppression Trial (CAST) Investigators. Preliminary report: effect of encainide and flecainide on mortality in a randomized trial of arrhythmia suppression after myocardial infarction. N Engl J Med 1989;321:406-12. https://doi.org/10.1056/NEJM198908103210629; PMID: 2473403.

78. Valembois L, Audureau E, Takeda A, et al. Antiarrhythmics for maintaining sinus rhythm after cardioversion of atrial fibrillation. Cochrane Database Syst Rev 2019;9:CD005049. https://doi.org/10.1002/14651858.CD005049.pub5; PMID: 31483500
79. Waldo AL, Camm AJ, deRuyter H, et al. Effect of d-sotalol on mortality in patients with left ventricular dysfunction after recent and remote myocardial infarction. The SWORD Investigators. Survival With Oral d-Sotalol. Lancet 1996;348:7-12. https://doi.org/10.1016/S0140-6736(96)021496; PMID: 8691967.

80. Tompkins C, Mclean R, Cheng A, et al. End-stage renal disease predicts complications in pacemaker and ICD implants. J Cardiovasc Electrophysiol 2011;22:1099-104 https://doi.org/10.1111/j.1540-8167.2011.02066.x; PMID: 21489029

81. Connolly SJ, Ezekowitz MD, Yusuf S, et al. Dabigatran versus warfarin in patients with atrial fibrillation. $N$ Engl $J$ Med 2009;361:1139-51. https://doi.org/10.1056/ NEJMoa0905561; PMID: 19717844

82. Granger CB, Alexander JH, McMurray JJV, et al. Apixaban versus warfarin in patients with atrial fibrillation. $N$ Engl $J$ Med 2011;365:981-92. https://doi.org.uk/10.1056/ NEJMoa1107039; PMID: 21870978.

83. Giugliano RP, Ruff CT, Braunwald E, et al. Edoxaban versus warfarin in patients with atrial fibrillation. N Engl J Med 2013;369:2093-104. https://doi.org/10.1056/ NEJMoa1310907; PMID: 24251359

84. Patel MR, Mahaffey KW, Garg J, et al. Rivaroxaban versus warfarin in nonvalvular atrial fibrillation. $N$ Engl J Med 2011;365:883-91. https://doi.org/10.1056/NEJMoa1009638; PMID: 21830957

85. Medicines and Healthcare products Regulatory Agency. Direct-acting oral anticoagulants (DOACs): reminder of bleeding risk, including availability of reversal agents. Drug Safety Update 2020;13:5-7. https://assets.publishing.service. gov.uk/government/uploads/system/uploads/attachment data/file/896274/June-2020-DSU-PDF.pdf (accessed 20 January 2022)

86. Parker $\mathrm{K}$, Thachil J. The use of direct oral anticoagulants in chronic kidney disease. Br J Haematol 2018;183:170-84. https://doi.org/10.1111/bjh.15564; PMID: 30183070.

87. Elis A, Klempfner R, Gurevitz C, et al. Apixaban in patients with atrial fibrillation and severe renal dysfunction: findings from a national registry. Isr Med Assoc J 2021;23:353-8. PMID: 34155848

88. De Vriese AS, Caluwé R, Van Der Meersch H, et al. Safety and efficacy of vitamin $\mathrm{K}$ antagonists versus rivaroxaban in hemodialysis patients with atrial fibrillation: a multicenter randomized controlled trial. J Am Soc Nephrol 2021;32:147483. https://doi.org/10.1681/ASN.2020111566; PMID: 33753537.

89. Kimachi M, Furukawa TA, Kimachi K, et al. Direct oral anticoagulants versus warfarin for preventing stroke and systemic embolic events among atrial fibrillation patients with chronic kidney disease. Cochrane Database Syst Rev 2017;11:CD011373. https://doi.org/10.1002/14651858. CD011373.pub2; PMID: 29105079

90. Genovesi S, Porcu L, Slaviero G, et al. Outcomes on safety and efficacy of left atrial appendage occlusion in end stage renal disease patients undergoing dialysis. J Nephrol 2021;34:63-73. https://doi.org/10.1007/s40620-020-007745; PMID: 3253583

91. Mansour M, Karst E, Heist EK, et al. The impact of first procedure success rate on the economics of atria fibrillation ablation. JACC Clin Electrophysiol 2017;3:129-38. https://doi.org/10.1016/j.jacep.2016.06.002; PMID: 29759385

92. Brüggenjürgen $\mathrm{B}$, Kohler $\mathrm{S}$, Ezzat $\mathrm{N}$, et al. Cost effectiveness of antiarrhythmic medications in patients suffering from atrial fibrillation. Pharmacoeconomics 2013;31:195-213. https://doi.org/10.1007/s40273-013-0028-7; PMID: 23444271.

93. Neovius M, Jacobson SH, Eriksson JK, et al. Mortality in chronic kidney disease and renal replacement therapy: a population-based cohort study. BMJ Open 2014;4:e004251. https://doi.org/10.1136/bmjopen-2013-004251; PMID: 24549162

94. Akhtar Z, Leung LWM, Sohal M, Gallagher MM. Leadless cardiac resynchronization therapy: a distant Utopia. Europace 2021;23:81. https://doi.org/10.1093/europace/ euab057; PMID: 33693629 